\title{
The Significance of Second Language Acquisition on Foreign Language Teaching
}

\author{
Xinli Liu \\ School of Foreign Studies, Xi’an University, Xi'an, Shaanxi, 710065
}

Keywords: Second Language Acquisition; Foreign Language Teaching; inspiration

\begin{abstract}
Second language acquisition mainly studies people's ability to acquire language ability, especially the ability to acquire foreign language. It involves linguistics, neurolinguistics, language education, sociology, etc. Now it has developed into a brand new discipline. In the second language acquisition theory, understanding the input language is a necessary condition for acquiring a second language. After the learner contacts the intelligible language input information or material, it intuitively produces the first physiological effect, which is human cognition understanding and accepting the universal reaction of new things, so second language acquisition theory has important reference meaning for foreign language teaching.
\end{abstract}

\section{Introduction}

First of all, behaviorism. The theory of behaviorism holds that language acquisition is a habit, which is formed by the learning subject's reaction through imitative and repeated responses to stimuli. In the second language acquisition process, the habits that are beneficial to language acquisition are the habits of positive migration. On the contrary, it is a negative transfer; and the theory of behaviorism also proposes systematic analysis and comparison of language elements such as phonetics, grammar, and vocabulary of the first language and second language. By analyzing the differences between the two, it can be concluded that the learning subject is acquiring Problems that may exist in the second language, and propose targeted solutions to promote the learning body to form a good learning habits to improve the effectiveness of second language acquisition.

Second, cognitive linguistics. In cognitive linguistics, researchers believe that human cognitive experience directly affects the effect of language acquisition. Language acquisition is also a human innate mechanism. Therefore, cognitive linguistics considers the subjectivity and subjective initiative of learning subjects to be crucial. It is important that language learning is not conducted mechanically or blindly. This is very important for language teaching. Therefore, foreign language teaching should fully mobilize the subjective initiative of students, inspire students' interest in learning, and enable students to actively and actively conduct second language acquisition.

Again, psycholinguistics. Psycholinguistics and cognitive linguistics are relatively close, but cognitive linguistics emphasizes the importance of practice for second language acquisition. Psycholinguistics focuses on theoretical research and focuses on the cognitive attributes and basis of second language acquisition. Psycholinguistics believes that attention and memory in the process of second language acquisition are inseparable from the learner's knowledge of language. A learner's conscious memory of certain words or language structures is beneficial to their long-term language acquisition, even if the learner It is repeated and strengthened, but it is easy to forget if it is not enough attention.

Finally, sociolinguistics. Sociolinguistics emphasizes the influence of the learning subject on the social environment and the communicative objects in the process of language acquisition. It advocates placing the second language acquisition into a specific language environment. The learning activity is close to the actual life of the learning subject. It is more favorable. Compared to the language environment and communication objects that naturally exist in first language acquisition, the acquisition environment and communication objects of the second language have great limitations. The attitudes of the social environment and the communicative objects will affect the psychological status of the subjects and the second language. The effect of the acquisition has a 
direct impact. Therefore, in the teaching process, the teacher must not only teach the knowledge content, but also take into account the student's psychological state and help the student to acquire a second language more effectively.

\section{The Main Factors Affecting Second Language Acquisition}

The main factors affecting second language acquisition include language factors and non-linguistic factors:

The main language factors affecting second language acquisition are language input. Language input refers to the language material that the learning subject can obtain. The process of internalizing these language materials is language absorption. Therefore, when teachers provide materials for learning subjects, they must Fully consider the actual situation of the learner, and determine the ratio of the input of the language material and the amount that the student can absorb according to their level. The second language acquisition theorizes that in language input, the language difficulty is higher than that of the learner's mastery of language knowledge and language ability. After the learner understands the language input material, even if the teacher does not explain the grammatical rules, they can master it. A higher level of language knowledge. Although this theory has not been verified in practical teaching, it can be used to refer to this theory when determining the difficulty of teaching. At the same time, the quantity and quality of language input must be emphasized in teaching.

The non-linguistic factors that affect second language acquisition are more complex, including age, intelligence, social and psychological factors, and learning strategies. Although the results of the current study do not support the theory that the younger the effect of learning a second language is, the better the theory is, but at least in speech, the smaller the age of learning a second language, the better. There is a direct correlation between the level of intellectual development and language ability, and the usual IQ test will also include language level measurement. Therefore, the overall learning or reasoning ability of the learning subject and the overall second language level directly reflect the learner's intelligence level. It is not that the higher the overall language ability is, the stronger the overall language ability is, but the overall intelligence level is the basis of the overall language ability, so the intelligence factor will have an important influence on learners' second language acquisition. Social factors and psychological factors will also affect the effect of second language acquisition to a certain extent, which is mainly reflected in the motivation and attitude of the learning subject. If the study subject has a positive learning attitude, the learning effect must be significantly better than the negative learning attitude. Students; and learning self-confidence, learning interest will also affect the learning effect of the learning body. In addition, learning strategies can also significantly influence the results of second language acquisition. A large number of research reports have proved that if the subject of learning explores a set of learning strategies that suits his or her own, it will also achieve excellent learning outcomes, to some extent even better than subjective efforts. Learning strategies refer to students' conscious and purposeful actions and skills in order to better acquire, store, and quote language information. Therefore, learning strategies are important prerequisites for achieving good results in second language acquisition.

\section{The Specific Application of Second Language Acquisition Theory in Foreign Language Teaching}

Vocabulary knowledge is the basis for learning a language. It is a basic guarantee for the subject to complete reading, and it is also the basis for acquiring other knowledge. The learner is the subject of language learning. The teacher should pay great attention to the study of vocabulary teaching and guide the students to master the vocabulary through repeated practice and memory. Common vocabulary learning methods include the following: First, learn the cards. Make vocabulary learning cards, use different colors to distinguish parts of speech or radicals, easy for students to remember; second, with the law. The more students learn vocabulary, the more prominent the problem of collocation limitation, collocation method can be applied to the whole process of language 
vocabulary learning. Finally, combine game methods. It allows students to collaborate freely in learning and integrate vocabulary knowledge into well-designed games such as crossword puzzles in English, gamers who dictate each other, games that guess the word cards, and so on. Vocabulary is the foundation of language acquisition, and it is also a process of continuous learning. Teachers should establish links between vocabulary learning elements such as linguistic, morphological, and semantic vocabulary, strengthen students' memory and mastery of vocabulary, and guide students to be flexible and actively use them. vocabulary.

The main value of grammar teaching lies in the accuracy of foreign language learners applying foreign languages, improving the effect of second language acquisition and the language level of learners. With the continuous development of second language acquisition theory, people gradually realize the importance of grammar teaching. Sex. In grammar teaching, on the one hand, the organic combination of the target language structure and the entire text can be achieved through discourse analysis. It provides a large number of contextual target language structure examples for the main body of the study from the overall perspective, emphasizing the extensive use of target language learning. Pure, simple words encourage learners to relate linguistic forms to linguistic meanings better; on the other hand, they can elaborate on the role of target language structures based on local descriptions. In foreign language classroom teaching, the rhetoric and application habits of native language grammar culture will negatively affect students' learning behavior. Traditional grammar teaching and writing are separated from each other. This teaching method not only reduces teaching efficiency due to repeated teaching, but also directly affects The systemic nature of second language acquisition. Therefore, in the grammar teaching process, the teacher should combine the language form and function, insist on starting from the difficulty grammar in the second language, and emphasize on cultivating the students' communicative competence and the ability to correctly use the language form.

The main function of language as a communication tool is to express the thinking and thinking of the language subject. Learning another new language besides the mother tongue requires a re-mastering of another language system, including pronunciation, symbols, and usage rules. Many learning subjects will Due to lack of self-confidence, I can't successfully express my true thoughts. Second language acquisition theory believes that social factors and psychological factors will have a direct impact on the second language acquisition effect of the subject. Therefore, in oral English teaching, teachers should take measures to help students establish their own language self confidence and encourage them to express themselves, express correctly, and accurately. Expression, gradually forming a new language self-image. Teachers should avoid correcting students' oral expression mistakes whenever and wherever possible, regardless of the occasion, so as not to undermine students' self-confidence in learning. The following measures can be taken to help students build self-confidence in learning: First, treat students to be tolerant and tolerant to students' language illusions. Try to use mild and patient evaluations to point out students' mistakes so that they do not attack their enthusiasm for learning. Second, we must establish a good language environment, try our best to create a training environment for the target language, strengthen students' listening training, and ensure the input of language. Using diversified teaching methods to design discussion topics that can promote students' imagination and willingness to express their own ideas, encourage students to express themselves courageously. Again, create a good classroom atmosphere. Different from other teachings, language teaching has a higher requirement for the lecturer's mood. Teachers must use positive emotions to infect students; or set up some lively and interesting teaching activities, teaching games, and simulated communication performances to stimulate students' initiative in learning. Participatory. Finally, persist in communicative training. The teacher needs to conduct orderly communication training from the expressions of words, sentences, and paragraphs according to the students' actual conditions, communication environment, and communication situations, and then let the students use language creatively.

Writing in foreign language learning is often a difficult point in language learning. The second language acquisition theory puts forward that the subject of learning must be able to apply the foreign language standard expression and use it flexibly. The expression of canonical sentences can 
lead students to actively reflect on the learning process, master the correct language expression skills through a large number of application practices, and activate students' endogenous motivation. As mentioned above, second language acquisition theory believes that non-linguistic factors will affect the learning effect of language. Therefore, teachers should pay attention to the influence of students' non-linguistic factors and write teaching from the following aspects: First, create a relaxed and harmonious writing. The environment eliminates students' fear of writing in foreign languages. Secondly, teaching students in accordance with their aptitude and progressing step by step in the teaching process. Using layered teaching methods to stimulate students' interest in learning at different levels. Finally, paying attention to scientific teaching evaluation and focusing on motivational evaluation. Enhance students' self-confidence in applying foreign language writing.

\section{Conclusion}

In short, the development of second language acquisition theory in our country is short, and our country's foreign language teaching environment also has a certain degree of particularity. The foreign theory is suitable for China's soil needs further verification. However, in practical foreign language teaching, the instructor must fully understand the gap between theory and practice, and study the second language acquisition in light of the actual characteristics of Chinese students in order to better analyze the general laws of Chinese students learning foreign languages and their cognitive psychology. The development process is to better solve the problems commonly found in foreign language teaching and establish a correct foreign language teaching guiding ideology to improve our overall foreign language teaching standards. The teacher should constantly update the teaching philosophy and teaching method in the classroom teaching, recognize the influencing factors of the second language acquisition, create a better language training environment for the students, form a good L2 language communication atmosphere, and improve the pertinence of language input. A reasonable grasp of the difficulty of language input to better train students' language skills and improve their second language acquisition.

\section{Acknowledgment}

Acknowledgements: This work was financially supported by Shaanxi Social science 2018 projects of major theoretical and practical problems research(2018Z001) and Shaanxi Civil-military integration research program(No.17JMR37) and Basic Research Projects of Weinan Technology Bureau(2017JCYJ-2-5).

\section{References}

[1] Dong Peipei. Krashen's Second Language Acquisition Theory and Foreign Language Teaching in China[J]. Journal of Yan'an Institute of Education, 2002(4):44-48.

[2] Hu Zhihong. The Application of "Second Language Acquisition" Theory in Modern Foreign Language Teaching [J]. Science and Technology Innovation, 2008(9):211-212.

[3] Yin Zhiping, Hao Xingyue. Explicit Grammar Teaching and Suggestive Grammar Teaching Discussion [J]. Journal of Yunnan Normal University, 2005 (2): 119-123.

[4] Dai Weidong, Chen Liping. A Review of the Theory of Second Language Grammar Teaching[J]. Foreign Language Teaching and Research, 2005(3):92-99.

[5] XIONG Renfang. A Preliminary Approach to the Grammar Teaching Method in the Basic Stage[J]. Journal of Beijing International Studies University,2005(2):81-84.

[6] Yao Junru. Language Learning Anxiety and the Implementation of Emotional Strategies [J]. New Curriculum Research X Journal, 2009 (1): 74-76

[7] Gu Jinzhi, Li Zheng milling. Causes of foreign language learning anxiety and countermeasures[J]. Education Journal, 2010(7):98-100,103. 